\title{
Virulence and Biotype Analyses of Hessian Fly (Diptera: Cecidomyiidae) Populations From Texas, Louisiana, and Oklahoma
}

Author(s): Sandra Garcés-Carrera, Allen Knutson, Haiyan Wang, Kristopher L. Giles , Fangneng Huang, R. Jeffrey Whitworth , C. Michael Smith , and Ming-Shun Chen

Source: Journal of Economic Entomology, 107(1):417-423. 2014.

Published By: Entomological Society of America

URL: http://www.bioone.org/doi/full/10.1603/EC13372

BioOne (www.bioone.org) is a nonprofit, online aggregation of core research in the biological, ecological, and environmental sciences. BioOne provides a sustainable online platform for over 170 journals and books published by nonprofit societies, associations, museums, institutions, and presses.

Your use of this PDF, the BioOne Web site, and all posted and associated content indicates your acceptance of BioOne's Terms of Use, available at www.bioone.org/page/terms of use.

Usage of BioOne content is strictly limited to personal, educational, and non-commercial use. Commercial inquiries or rights and permissions requests should be directed to the individual publisher as copyright holder. 


\title{
Virulence and Biotype Analyses of Hessian Fly (Diptera: Cecidomyiidae) Populations From Texas, Louisiana, and Oklahoma
}

\author{
SANDRA GARCÉS-CARRERA, ${ }^{1}$ ALLEN KNUTSON,${ }^{2}$ HAIYAN WANG,${ }^{3}$ KRISTOPHER L. GILES,${ }^{4}$ \\ FANGNENG HUANG ${ }^{5}$ R. JEFFREY WHITWORTH ${ }_{,}^{1}$ C. MICHAEL SMITH, ${ }^{1}$ \\ AND MING-SHUN CHEN ${ }^{1,6,7}$
}

J. Econ. Entomol. 107(1): 417-423 (2014); DOI: http://dx.doi.org/10.1603/EC13372

\begin{abstract}
Hessian fly, Mayetiola destructor (Say, 1817), is a major pest of wheat, and is controlled mainly through deploying fly-resistant wheat cultivars. The challenge for the plant resistance approach is that virulence of Hessian fly populations in the field is dynamic, and wheat cultivars may lose resistance within $6-8 \mathrm{yr}$. To ensure continuous success of host plant resistance, Hessian fly populations in the field need to be constantly monitored to determine which resistance genes remain effective in different geographic regions. This study investigated five Hessian fly populations collected from Texas, Louisiana, and Oklahoma, where infestation by Hessian fly has been high in recent years. Eight resistance genes, $\mathrm{H12}, \mathrm{H13}, \mathrm{H17}, \mathrm{H1}$, $\mathrm{H} 22, \mathrm{H} 25, \mathrm{H} 26$, and $\mathrm{Hdic}$, were found to be highly effective against all tested Hessian fly populations in this region, conferring resistance to $\geq 80 \%$ of plants containing one of these resistance genes. The frequencies of biotypes virulent to resistance genes H13 (biotype vH13), H18 (vH18), H21 (vH21), H25 (vH25), H26 (vH26), and Hdic (vHdic) were determined, and were found to vary from population to population, ranging from 0 to $45 \%$. A logistic regression model was established to predict biotype frequencies based on the correlation between the percentages of susceptible plants obtained in a virulence test and the log-odds of virulent biotype frequencies determined by a traditional approach.
\end{abstract}

KEY WORDS Mayetiola destructor, Hessian fly, biotype, wheat, plant resistance

Hessian fly, Mayetiola destructor (Say, 1817), has been a major pest of wheat since it was brought to the United States around 1779 during the American Revolutionary War (Buntin 1999, Pauly 2002). The Hessian fly can damage wheat plants from seedling to reproductive stages. In seedling plants, Hessian fly larvae feed between leaf sheaths, resulting in growth inhibition and the death of the infested plant unless a new tiller develops (Byers and Gallun 1971). In reproductive plants, larvae feed on the stem, resulting in plant lodging and reduced grain filling. In recent years,

\footnotetext{
Mention of trade names or commercial products in this publication is solely for the purpose of providing specific information and does not imply recommendation or endorsement by the U.S. Department of Agriculture. USDA is an equal opportunity provider and employer.

${ }^{1}$ Department of Entomology, Kansas State University, 123 Waters Hall, Manhattan, KS 66506.

${ }^{2}$ Department of Entomology, Texas AgriLife Research and Extension Center, Texas A\&M University, 17360 Coit Rd., Dallas, TX 75252

${ }^{3}$ Department of Statistics, Kansas State University, 101 Dickens Hall, Manhattan, KS 66506.

${ }^{4}$ Department of Plant Pathology and Entomology, Oklahoma State University, 127 NRC, Stillwater, OK 74078.

${ }^{5}$ Department of Entomology, Louisiana State University Agricultural Center, 404 Life Science Bldg., Baton Rouge, LA 70803-1710.

${ }^{6}$ Hard Winter Wheat Genetics Research Unit, Center for Grain and Animal Health, USDA-ARS, 1515 College Ave., Manhattan, KS 6650

${ }^{7}$ Corresponding author, e-mail: mchen@ksu.edu or ming-shun. chen@ars.usda.gov.
}

Hessian fly outbreaks have occurred more frequently, especially in the southwestern United States, probably owing to no-till cultivation and climate change (Clement et al. 2003, Royer 2005, Watson 2005, Comis 2007, Knutson and Swart 2007, Smith 2007, Huang et al. 2011).

Currently, Hessian fly can be suppressed by seed treatment with systemic pesticides, late planting to avoid infestation in the fall (so called fly-free date), and deployment of resistant wheat cultivars (Buntin and Bruchner 1990, Buntin and Hudson 1991, Buntin 1992, Buntin et al. 1992, Morgan et al. 2005, Giles and Royer 2011). Among these control measures, deployment of resistant cultivars is the most economic and effective means to reduce Hessian fly infestations. Seed treatment is only effective for $\approx 14 \mathrm{~d}$, and late planting can only be adopted in the northern United States, and the fly-free day varies from year to year. Currently, 34 resistance genes have been identified and many of them have been deployed to the field $(\mathrm{Li}$ et al. 2013). All resistance genes except $h 4$ are inherited as dominant traits with antibiosis effects on fly larvae. A reliable host plant resistance strategy remains a challenge because Hessian fly field populations are dynamically changing, and the effectiveness of deployed resistance genes is relatively short lived (Ratcliffe and Hatchett 1997, Gould 1998, Ratcliffe et 
al. 2000). Rare and uncommon biotypes virulent to specific resistance genes can become prevalent owing to selection pressure after resistance genes have been deployed. Even without selection pressure from deployed resistance genes, Hessian fly populations are constantly evolving in the field owing to genetic adaptation mechanisms formed in the long course of wheat-Hessian fly coevolution (Chen et al. 2010). To safeguard the effectiveness of the plant resistance strategy, the virulence of Hessian fly populations in different regions must be constantly monitored so that breeders and producers know which resistance genes remain effective in their regions, and which biotypes are currently prevalent.

In the southern United States including states of Georgia, Oklahoma, and Texas, Hessian fly has historically been a major problem of wheat production. In recent years, heavy infestations have become more frequent and occurred in larger areas in Oklahoma and Texas (Royer 2005, Watson 2005, Comis 2007, Knutson and Swart 2007, Smith 2007, Alvey 2009). Hessian fly damage had not been observed until 1989 in Louisiana (Colyer et al. 1989), where the pest has recently become a serious problem of wheat production (Huang et al. 2011). Hessian fly field virulence was first reported in Texas and Oklahoma in 2007 (Chen et al. 2009) and then in Georgia and several other southern states (Cambron et al. 2010). The objectives of the current study were to provide current information on Hessian fly virulence and biotype compositions in field populations collected from heavily infested areas in Texas, Louisiana, and Oklahoma, and to establish a method to estimate biotype frequency based on results of virulence assays so that the time-consuming process for direct biotype analysis of individual females can be avoided in the future.

\section{Materials and Methods}

Hessian Fly Samples. Hessian fly populations were sampled by collecting wheat plants infested with Hessian fly in pupal (so called flaxseeds) stage. Infested plants were packed in boxes, sent to the U.S. Department of Agriculture's-Agricultural Research Service (USDA-ARS) Hessian Fly Research Laboratory in Manhattan, KS, and stored in a cold room for $180 \mathrm{~d}$ to break diapause before assaying for virulence and biotype. During 2010-2011, Hessian fly populations from Grayson, McClennan, and Hill Counties in Texas were collected and evaluated. A population collected in 2008 from Grayson County, TX, had been previously analyzed (Chen et al. 2009). Hessian fly populations from McClennan and Hill counties, TX, had not been evaluated since 1987 (Hoelscher et al. 1987). These samples were designated as Grayson-TX-FD-11, McClennon-TX-FD-10, and Hill-TX-FD-11, respectively. FD represents "field" samples analyzed directly without increasing the population in greenhouse. A Hessian fly population from Franklin Parish, LA $\left(32^{\circ}\right.$ $08^{\prime} 32.09^{\prime \prime} \mathrm{N}, 91^{\circ} 40^{\prime} 50.20^{\prime \prime} \mathrm{W}$ ), was collected in 2011 , and a population from Okeene, OK, collected in 2012. Before the current study, the status of Hessian fly virulence in these two locations was unknown. Owing to their small size, the Oklahoma and Louisiana populations were increased in the greenhouse for one generation before analyses, and were designated as Franklin-LA-GH-11 and Okeene-OK-GH-12, respectively (GH-“greenhouse" increased).

Greenhouse Increase of Hessian Fly Populations. For the two populations from Louisiana and Oklahoma, each contained roughly $\approx 2,000$ pupae, which were not enough for direct assays. These two samples were increased one time in greenhouse. For greenhouse increase, wheat stubbles collected from fields were placed into a mesh tent ( 243.8 by 61 by $91.4 \mathrm{~cm}$ ) in the greenhouse to facilitate Hessian fly adult emergence. When adult flies started to emerge, $\approx 3,500$ seedlings of 'Karl 92,' a Hessian fly-susceptible cultivar, at the 1.5 leaf stage were placed into the cage to collect eggs. Adult flies were allowed to lay eggs on the plants for 3-5 d, depending on egg densities. When egg density reached an average of $\approx 8$ eggs per plant, seedlings were transported to a different greenhouse location to allow eggs to hatch and larvae to develop to pupation. Newly obtained pupae were collected along with wheat seedlings and stored in a cool room for at least 3 mo before assays (Chen et al. 2009).

Virulence Analysis. A set of 22 wheat cultivars, each carrying a different Hessian fly-resistance gene or gene combination, was assembled. This set of wheat cultivars contained resistance genes $\mathrm{H} 3, \mathrm{H} 5, \mathrm{H} 6, \mathrm{H} 7$ / H8, H9, H10, H11, H12, H13, H14, H16, H17, H18, H19, H21, H22, H23, H24, H25, H26, H31, and Hdic. Twenty to 25 seeds of each testing line were planted in a row in a randomized design in a 54 - by 36 - by 8 -cm flat, which included two rows of Karl-92 in the middle of each flat. To maintain Hessian fly populations, additional flats of Karl-92 seedlings were planted and used to collect eggs. Wheat stems containing Hessian fly pupae were placed into a $243.8-$ by $61-$ by $91.4-\mathrm{cm}$ greenhouse tent $3 \mathrm{~d}$ before the virulence test to facilitate Hessian fly adult emergence. Water was sprayed daily onto the tent to maintain moisture. When Hessian fly adults started to emerge, seedlings at the 1.5 leaf stage were placed inside the same tent for infestation.

Female flies oviposit on the adaxial surface of plants in a free-choice manner. To reduce variations in the test results, infestation was terminated when the number of eggs reached an average of 8 eggs per plant (Chen et al. 2009). Plants were categorized as susceptible or resistant $21 \mathrm{~d}$ after infestation. Plants were recorded as resistant if they contained dead (slim and reddish) first-instar larvae and were growing normally. Plants were recorded as susceptible if they were stunted and contained live (fat and white) larvae. Plants with no dead or alive larvae were categorized as escapes and were excluded from analysis.

As described previously (Chen et al. 2009), a gene was defined as highly resistant to a Hessian fly population if $\geq 80 \%$ plants of the wheat variety containing the gene were resistant to the Hessian fly population in a virulence assay. A gene was considered as moderately resistant to a fly population if $50-80 \%$ plants of 
the variety containing the gene were resistant, while a gene was considered susceptible if $<50 \%$ plants of the variety containing the gene were resistant.

Analysis of Biotype Composition. Cultivars that contain one of the six resistance genes $H 13, H 18, H 21$, H25, H26, and Hdic, and had shown at least $80 \%$ of resistant plants to a Texas field population in a previous test (Chen et al. 2009) were selected to determine Hessian fly biotype frequencies. Biotype composition was determined using a procedure similar to that described by Ratcliffe et al. (1994). Briefly, a pot was divided into four sections, and each section was planted with a susceptible control (the cultivar Karl92) and a combination of three resistant cultivars (either a combination of cultivars each containing $\mathrm{H} 13, \mathrm{H} 18$, or $\mathrm{H} 21$; or a combination of cultivars each containing $H 25, H 26$, or Hdic). After germination, five seedlings were kept for each cultivar and excess plants were removed. At one leaf stage, seedlings in each pot were caged and infested with a single mated female. A female can produce $\approx 200$ eggs and has the behavior to distribute eggs roughly evenly among plants the fly can access. Three weeks after infestation, plants were phenotyped. If susceptible control plants in a pot showed the typical susceptible symptom, the assay for that pot was considered successful. Further examination was carried out for each resistant plant to see if dead larvae can be found. A plant containing dead larvae was considered resistant; a plant containing live larvae was considered susceptible; and a plant containing no larva was considered an escape. If susceptible control plants in a pot showed no sign of Hessian fly infestation, the assay for that pot was considered a failure and was excluded from further analysis.

Relationship Between Percentages of Susceptible Plants and Virulence. Chi-square tests were performed using percentage of resistant plants in virulence tests to determine if fly populations were dependent on cultivars that carry different resistance genes. A $P$ value of $<0.0005$ suggests that resistance genes are not independent of Hessian fly populations. The percentages of resistant plants obtained with different fly populations were compared using ANOVA of virulence test data for each resistance gene. Twenty-two resistance genes were tested and a multiple comparison adjustment based on Bonferroni correction (Bonferroni 1935) was made to declare significance for each test. A virulence test was considered significant at the $\alpha=0.05$ level when the $P$ value was $\leq 0.0022(0.05 / 22)$. For a test yielding a significant $P$ value, pairwise comparisons were conducted using the Tukey's Honestly Significant Difference (HSD) method to identify populations differing from others on percentages of resistant plants. The Tukey's HSD adjusted $P$ values were obtained and compared with 0.05 to identify populations that differ significantly in the percentages of resistant plants for each gene.

To model the relationship between biotype composition and the percentages of susceptible plants, a logistic regression model was developed, using the counts of virulent and avirulent fly females as the response variable. Significance predictors included in the model were the percentages of susceptible plants in virulence tests, the type of resistance gene, and their interaction. All predictors were highly significant at $P \leq 0.01$ (the $P$ values based on deviance test from the logistic regression model for these factors or variables are $<2.2 \times 10^{-16}, 2.133 \times 10^{-8}$, and 0.0011 , respectively). Pearson correlation coefficients between the observed percent of virulent biotypes and their predicted value from the logistic model were calculated. All the statistical analyses were conducted with $\mathrm{R}$ version 3.0.1 (http:// cran.r-project.org/).

\section{Results}

Virulence of Three Texas Fly Populations. Eight genes, H12, H13, H17, H18, H21, H22, H25, H26, and Hdic, were highly resistant to all three Texas Hessian fly populations, conferring resistance in $\geq 80 \%$ of plants containing one of these genes to the three fly populations (Table 1), a level considered highly effective based on historic observations (Ratcliffe et al. 2000, Chen et al. 2009, Cambron et al. 2010). In addition, $H 3$ or $H 11$ conferred resistance in $\geq 80 \%$ of plants containing either of these genes to the GraysonTX-FD-11 and Hill-TX-FD-11 populations. Cultivars containing $H 9, H 16, H 19$, or $H 23$, exhibited moderate resistance, having at least $50 \%$ plants resistant to at least one of the three Texas populations. The H6, $H 7 H 8, H 10, H 14, H 24$, and $H 31$ genes or gene combination conferred resistance in $<50 \%$ of plants containing one of the genes to any one of the three Texas populations.

Virulence of a Louisiana Fly Population. Fourteen genes, H3, H9, H12, H13, H16, H17, H18, H19, H21, H22, H24, H25, H26, and Hdic, were highly effective against the Franklin-LS-GH-12 population, conferring resistance in $80 \%$ or more of plants containing one of these genes (Table 1). H10, H14, and H23 exhibited moderate resistance, conferring resistance in $50-80 \%$ of plants containing one of the genes. $H 5, H 6, H 7 H 8, H 31$ were the least effective genes, conferring resistance in only $\leq 50 \%$ of plants containing one of these genes.

Virulence of an Oklahoma Fly Population. H3, H5, H6, H12, H13, H17, H18, H19, H21, H22, H25, H26, and Hdic were highly effective against the Okeene-OKGH-12 population, conferring resistance in $\geq 80 \%$ of plants containing one of these genes (Table 1). H9, $H 10, H 11$, and $H 16$ exhibited moderate resistance, conferring resistance in $50-80 \%$ of plants containing one of the genes, and $H 7 H 8, H 14, H 23, H 24$, and $H 31$ were less effective, conferring resistance in only $\leq 50 \%$ of plants containing one of these genes.

Differences in Virulence Among Different Fly Populations. Significant differences were observed in the percentages of resistant plants carrying H11, H16, or H24 to the three Texas populations, with $P$ values $2.94 \times 10^{-4}, 1.59 \times 10^{-3}$, and $5.92 \times 10^{-4}$, respectively (Table 1). When all five populations are compared, the percentages of resistant plants showed differences among some populations for the following genes $(P$ value in parenthesis $): H 5\left(3.93 \times 10^{-4}\right), H 6(1.27 \times$ $\left.10^{-5}\right), H 9\left(1.16 \times 10^{-4}\right), H 11\left(4.11 \times 10^{-5}\right), H 14$ 
Table 1. Percent \pm SD Hessian fly resistance in plants with different Hessian fly resistance genes resistant to Hessian fly populations from Texas, Louisiana, and Oklahoma

\begin{tabular}{|c|c|c|c|c|c|c|}
\hline \multirow{2}{*}{$\mathrm{R}$ gene } & \multirow{2}{*}{ Wheat cultivar } & \multicolumn{5}{|c|}{ Percent \pm SD resistant plants } \\
\hline & & Grayson-TX-FD-11 & McLennan-TX-FD-10 & Hill-TX-FD-11 & Franklin-LA-GH-11 & Okeene-OK-GH-12 \\
\hline H3 & Ike & $91 \pm 1.3$ & $70 \pm 3.3$ & $80 \pm 2.8$ & $94 \pm 1.3$ & $97 \pm 2.2$ \\
\hline H5 & Magnun & $82 \pm 4.7$ & $51 \pm 3.6$ & $63 \pm 5$ & $6 \pm 1.2$ & $81 \pm 1.0$ \\
\hline H6 & Cadwell & $8 \pm 1$ & $35 \pm 1.8$ & $46 \pm 1$ & $23 \pm 1.8$ & $88 \pm 5.0$ \\
\hline H7H8 & Seneca & ND & $22 \pm 1.7$ & ND & $16 \pm 2.9$ & ND \\
\hline H9 & Iris & $32 \pm 3.1$ & $79 \pm 1.3$ & $56 \pm 3.9$ & $100 \pm 1.5$ & $54 \pm 2.2$ \\
\hline H1O & Joy & $47 \pm 3.4$ & $31 \pm 1.0$ & $40 \pm 3.6$ & $75 \pm 2.5$ & $69 \pm 3.1$ \\
\hline H11 & Karen & $100 \pm 1.7$ & $39 \pm 1.4$ & $88 \pm 2.6$ & $32 \pm 1.3$ & $73 \pm 2.2$ \\
\hline $\mathrm{H} 12^{a}$ & Lola $^{a}$ & $96 \pm 1.9^{a}$ & $80 \pm 3.5^{a}$ & $84 \pm 1.3^{a}$ & $100 \pm 0.6^{a}$ & $98 \pm 4.8^{a}$ \\
\hline$H 13^{a}$ & Molly $^{a}$ & $93 \pm 1.7^{a}$ & $96 \pm 1.0^{a}$ & $96 \pm 1.3^{a}$ & $100 \pm 0.8^{a}$ & $100 \pm 2.1^{a}$ \\
\hline$H 14$ & D6647-H14 & $17 \pm 1.2$ & $14 \pm 1.4$ & ND & $69 \pm 5.4$ & $18 \pm 1.6$ \\
\hline H16 & D6647-H16 & $75 \pm 1.4$ & $32 \pm 1.4$ & $78 \pm 3.3$ & $100 \pm 1.0$ & $73 \pm 5.6$ \\
\hline $\mathrm{H} 17^{a}$ & $\mathrm{D} 6647-\mathrm{H} 17^{a}$ & $90 \pm 2.6^{a}$ & $83 \pm 2.9^{a}$ & $88 \pm 2^{a}$ & $92 \pm 4.3^{a}$ & $97 \pm 3.5^{a}$ \\
\hline$H 18^{a}$ & Redland $^{a}$ & $97 \pm 0.8^{a}$ & $88 \pm 1.7^{a}$ & $92 \pm 4.3^{a}$ & $100 \pm 1.3^{a}$ & $100 \pm 4.7^{a}$ \\
\hline H19 & $84702 \mathrm{~B} 14$ & $79 \pm 5.7$ & $17 \pm 1.3$ & $27 \pm 1.7$ & $100 \pm 1.3$ & $86 \pm 3.9$ \\
\hline H21 & Hamlet & $80 \pm 1.5$ & $69 \pm 0.8$ & $87 \pm 1.4$ & $90 \pm 1.5$ & $82 \pm 6.8$ \\
\hline $\mathrm{H} 22^{a}$ & KSWRCG $01^{a}$ & $100 \pm 1.3^{a}$ & $98 \pm 0.8^{a}$ & $96 \pm 2.1^{a}$ & $100 \pm 1.5^{a}$ & $100 \pm 0.6^{a}$ \\
\hline $\mathrm{H} 23$ & KSWRCG 06 & $54 \pm 2.4$ & $39 \pm 1.2$ & $32 \pm 2.6$ & $53 \pm 1.7$ & $30 \pm 5.3$ \\
\hline $\mathrm{H} 24$ & KSWRCG 03 & $32 \pm 1$ & $1 \pm 0.5$ & $27 \pm 1.9$ & $97 \pm 1.8$ & $35 \pm 3.5$ \\
\hline $\mathrm{H} 25^{a}$ & KSWRCG $20^{a}$ & $93 \pm 2.4^{a}$ & $95 \pm 1.0^{a}$ & $92 \pm 3.4^{a}$ & $94 \pm 0.8^{a}$ & $97 \pm 2.7^{a}$ \\
\hline H2 $6^{a}$ & KSWRCG $26^{a}$ & $91 \pm 2.6^{a}$ & $92 \pm 0.6^{a}$ & $93 \pm 2.5^{a}$ & $95 \pm 0.6^{a}$ & $99 \pm 1.0^{a}$ \\
\hline$H 31$ & P921696Al & $17 \pm 1.8$ & $15 \pm 0.8$ & $11 \pm 1.8$ & $44 \pm 3.1$ & $34 \pm 0.0$ \\
\hline $\mathrm{Hdic}^{a}$ & KSWRCG $42^{a}$ & $100 \pm 3.2^{a}$ & $98 \pm 1.5^{a}$ & $99 \pm 1.2^{a}$ & $100 \pm 1.5^{a}$ & $100 \pm 4.7^{a}$ \\
\hline
\end{tabular}

${ }^{a}$ Plants exhibiting $\geq 80 \%$ resistance to all five populations.

Bold font indicates plants exhibiting $\geq 80 \%$ resistance.

ND, not determined; SD, standard error.

$\left(5.63 \times 10^{-4}\right), H 19\left(1.35 \times 10^{-3}\right), H 24\left(4.39 \times 10^{-8}\right)$, and H31 $\left(1.79 \times 10^{-3}\right)$. However, H12, H13, H17, H18, H22, H25, H26, and Hdic showed more consistent data in conferring resistance in wheat seedlings to the five different geographic Hessian fly infestations.

Biotype Composition. Although 100 females from each of the three Texas populations were analyzed, success rates were only $54-83 \%$, as some females failed to oviposit (Table 2). The percentages of biotypes virulent to the wheat resistance genes H13 (biotype vH13), H18 (vH18), H21 (vH21), H25 (vH25), H26 (vH26), and Hdic (vHdic) ranged from 0 to $16 \%$ for the Grayson-TX-FD-11 population; 1 to $45 \%$ for the McClennan-TX-FD-10 population; and 2 to $22 \%$ for the Hill-TX-FD-11 population.
In the Louisiana and Oklahoma populations, fewer females were analyzed owing to limited availability of mated females when plants were at the appropriate stage for evaluation. The virulence frequencies of the Oklahoma and Louisiana populations were much lower. The frequency of $\mathrm{vH} 13, \mathrm{vH} 18, \mathrm{vH} 21, \mathrm{vH} 25$, vH26, and vHdic was 0 to $14 \%$ for the Franklin-LSGH-12 population, and 0 to $27 \%$ for the Okeene-OKGH-12 population.

Relationship Between Percentages of Susceptible Plants and Virulence. Biotype frequency analyses were conducted simultaneously at the same time as virulence assays on the five Hessian fly populations (Table 2). The percentages of susceptible plants obtained in virulence tests conveyed strong information

Table 2. Biotype composition of Hessian fly populations from Louisiana, Oklahoma, and Texas

\begin{tabular}{|c|c|c|c|c|c|c|c|}
\hline \multirow{2}{*}{ Hessian fly pop } & \multirow{2}{*}{ Virulence } & \multicolumn{6}{|c|}{ Hessian fly resistance gene } \\
\hline & & $H 13$ & $H 18$ & $H 21$ & $H 25$ & $H 26$ & Hdic \\
\hline \multirow[t]{3}{*}{ Grayson-TX-FD-10 } & No. avirulent & 80 & 79 & 70 & 75 & 72 & 83 \\
\hline & No. virulent & 3 & 4 & 13 & 8 & 11 & 0 \\
\hline & $\%$ virulent & 4 & 5 & 16 & 10 & 13 & 0 \\
\hline \multirow[t]{3}{*}{ McClennan-TX-FD-10 } & No. avirulent & 68 & 65 & 38 & 52 & 74 & 79 \\
\hline & No. virulent & 1 & 17 & 31 & 17 & 8 & 3 \\
\hline & $\%$ virulent & 1 & 21 & 45 & 25 & 10 & 4 \\
\hline \multirow{3}{*}{ Hill-TX-FD-10 } & No. avirulent & 61 & 44 & 50 & 50 & 47 & 53 \\
\hline & No. virulent & 3 & 10 & 14 & 14 & 7 & 1 \\
\hline & $\%$ virulent & 5 & 19 & 22 & 22 & 13 & 2 \\
\hline \multirow[t]{3}{*}{ Franklin-LS-GH-11 } & No. avirulent & 21 & 54 & 18 & 19 & 48 & 54 \\
\hline & No. virulent & 0 & 0 & 3 & 2 & 6 & 0 \\
\hline & $\%$ virulent & 0 & 0 & 14 & 10 & 11 & 0 \\
\hline \multirow[t]{3}{*}{ Okeene-OK-GH-12 } & No. avirulent & 22 & 54 & 16 & 18 & 49 & 54 \\
\hline & No. virulent & 0 & 0 & 6 & 4 & 5 & 0 \\
\hline & $\%$ virulent & 0 & 0 & 27 & 18 & 9 & 0 \\
\hline
\end{tabular}

$\%$ virulent $=$ percentage of Hessian fly female offspring virulent to the corresponding wheat resistance gene 

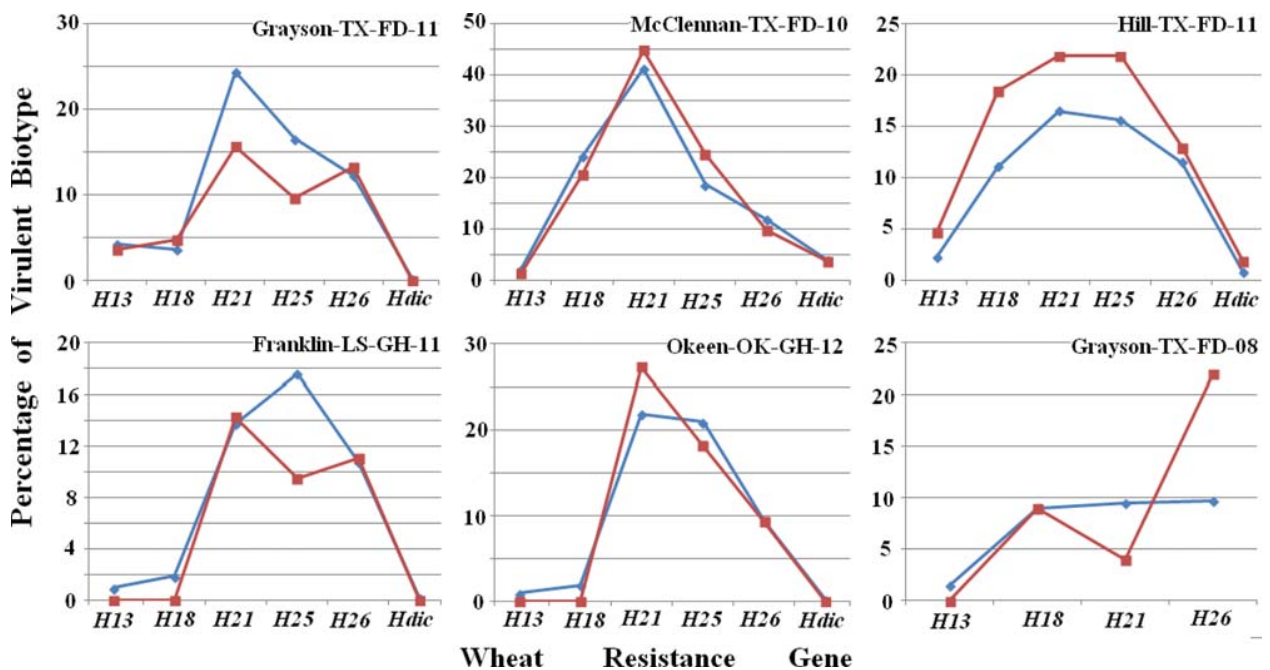

Fig. 1. Biotype frequency prediction based on virulence test results. The curves with squares represent the actual biotype frequencies obtained following the procedure described by Ratcliffe et al. (1994) (Table 2). The data shown in the last graph with the Grayson-TX-FD-08 were based on results of a previous report (Chen et al. 2009). (Online figure in color.)

about the frequencies of virulent biotypes obtained in biotype analyses. A logistic regression model, $y=$ $100\left(1+\mathrm{e}^{-\mathrm{f}(\mathrm{x})}\right)$, was established with data from these two analyses, where $\mathrm{y}$ is the percentages of virulent biotypes and $f(x)$ is a function of the percentages of susceptible plants (percSP) in a virulence assay with cultivars carrying a specific resistance gene (Fig. 1). Mathematically, $\mathrm{f}(\mathrm{x})=-4.629+0.668 \times \mathrm{I}($ Gene $=$ 'H18' $)+2.086 \times \mathrm{I}\left(\right.$ Gene $={ }^{\prime} H 21$ ' $)+3.521 \times \mathrm{I}($ Gene $=$ $' H 25 ')+2.326 \times \mathrm{I}\left(\right.$ Gene $={ }^{`} H 26$ ' $)-1.869 \times \mathrm{I}($ Gene $=$ 'Hdic' $)+0.217 \times$ percSP $+0.0178 \times \mathrm{I}($ Gene $=$ 'H18') $\times$ percSP $-0.147 \times \mathrm{I}($ Gene $=$ 'H21') $\times$ percSP $-0.290 \times \mathrm{I}\left(\right.$ Gene $\left.={ }^{\prime} H 25 ’\right) \times$ percSP $0.180 \times \mathrm{I}\left(\right.$ Gene $={ }^{\prime} H 26$ ' $) \times$ percSP $+1.44 \times \mathrm{I}($ Gene $=$ 'Hdic') $\times$ percSP, and $\mathrm{I}$ (condition) is an indicator function that takes value 1 if the condition is true and takes value 0 if the condition is false. The formula can be simplified to $\mathrm{y}=100\left(1+\mathrm{e}^{-(\mathrm{B}+\mathrm{b}+\mathrm{Kx}+\mathrm{kx})}\right)$ for $\mathrm{a}$ specific calculation, where $\mathbf{B}$ is the Intercept, $\mathrm{b}$ is the modification factor to the intercept associated with a specific resistance gene, $\mathrm{K}$ is the slope, and $\mathrm{k}$ is the modification factor to the slope associated with a specific resistance gene, and $\mathrm{x}$ is percSP for a specific resistance gene. For example, to calculate the predicted biotype vH18 based on the Grayson-TX-FD-11, the calculation is: $\mathrm{y}=100\left(1+\mathrm{e}^{-(\mathbf{B}+\mathrm{b}+\mathrm{Kx}+\mathrm{kx})}\right)=$ $100\left(1+\mathrm{e}^{-(-4.629+0.668+0.217 \mathrm{x}+0.0178 \mathrm{x})}\right)^{-1}=100 /(1$ $\left.+\mathrm{e}^{-(-4.629+0.668+0.217(3)+0.0178(3))}\right)=3.7 \%$.

The model was used to predict biotype frequencies, and yielded predicted values similar to and highly correlated with actual observed values $(r=0.93,95 \%$ CI of the correlation is $[0.86,0.97]$; $P$ value $<8.4$; Fig. $1)$. We further tested the model with data reported by Chen et al. (2009), and the predicted frequencies of biotypes virulent to $H 13$ (vH13) and H18 (vH18) are fairly consistent with the observed values (Fig. 1, Grayson-TX-FD-08). However, the predicted frequencies for biotypes vH21 and $\mathrm{vH} 26$ are 9.5 and $9.7 \%$, respectively, which differ from the corresponding observed frequencies of 4 and $22 \%$, respectively.

\section{Discussion}

Variation in virulence among Hessian fly populations from different regions has been observed previously (Chen et al. 2009, Cambron et al. 2010). In this study, we also observed variation in virulence among the five regional populations (Table 1). Specifically, wheat cultivars carrying H11, H16, or H24 showed significant difference in percentages of resistant plants among the three Texas populations. Wheat cultivars carrying H5, H6, H9, H11, H14, H19, H24, or H31 showed significant difference in percentages of resistant plants when all five populations were compared. For example, $94 \%$ of the plants with the $H 5$ gene were susceptible to the Franklin-LA-GH-11 population, whereas only $18 \%$ of plants with this gene were susceptible to the Grayson-TX-FD-11. Variation in sample collection and testing conditions might have partially affected results, but the standardized virulence detection procedure yields fairly consistent results as described previously (Chen et al. 2009). Thus, the variation in population virulence was likely owing to differences in biotype composition of the five Hessian fly populations. Among possible factors that might have caused difference in population virulence, regional selection pressure from deployment of cultivars containing specific resistance genes is likely playing a role. This can be seen from the detection of the most virulent Hessian fly population to date in Kay County in Oklahoma, the nursery site where new cultivars containing various Hessian fly resistance genes are being tested (Chen et al. 2009). The virulence of the Kay County population is different from that of populations collected from neighboring regions including the Okeene-OK-GH-12 population. Only six resis- 
tance genes (H13, H21, H22, H25, H26, and Hdic) conferred resistance in $\geq 80 \%$ of plants to Hessian fly infestation in a sample collected from Kay county in 2006 (Chen et al. 2009). In comparison, 13 resistance genes conferred resistance in $\geq 80 \%$ of plants to Hessian fly in the Okeene-OK-GH-12 population (Table $1)$. Another possible reason for virulence variation among regional Hessian fly populations is the intrinsic mechanism that allows Hessian fly to constantly generate genetic diversity in genes likely involved in virulence, which include large numbers of genes encoding putative effector proteins (Chen et al. 2010).

One of the main objectives of this study was to provide information on which resistance genes are still effective to Hessian fly populations in the field in three southern states. Despite the variation in virulence described previously, some resistance genes conferred resistance against all of the Hessian fly populations tested. As shown in Table $1, \geq 80 \%$ of plants containing H12, H13, H17, H18, H22, H25, H26, or Hdic, were resistant to all five tested populations, indicating that these genes remain highly effective in protecting wheat in these regions. Hdic, a newly identified resistance gene from Triticum turgidum ssp. dicoccum (Liu et al. 2005), exhibited the highest effectiveness, conferring resistance in $>98 \%$ of plants containing Hdic to all five fly populations. In addition, $H 3$ and $H 21$ also conferred resistance in $\geq 80 \%$ plants to four of the five populations, and in nearly $70 \%$ plants to the McClennan-TX-FD-10 population. However, $H 3$ was reported to be ineffective to other populations collected from southern United States (Cambron et al. 2010). Accordingly, we recommend that $H 12, H 13, H 17, H 18$, H22, H25, H26, and Hdic to be used in breeding programs against Hessian fly infestations in Texas, Louisiana, and Oklahoma.

The determination of biotype frequencies in field populations is time consuming, and becomes increasingly unachievable as the numbers of the identified resistance genes increase. In the wheat-Hessian fly interaction, a previous study indicated that the frequency of a virulent biotype is proportional to the percentage of susceptible plants that carry a resistance gene in a virulence test (Chen et al. 2009). In the current study, a logistic regression model predicted frequencies of biotypes virulent to some genes, but was less reliable for other genes. This discrepancy indicates that further data accumulation and improvement of model parameters are needed for more accurate biotype predictions. In our logistic regression model, there are two factors that affect the prediction of biotype frequencies. One was, of course, the percentage of susceptible plants in a virulence test. The higher the percentage of susceptible plants was, the higher the frequency of the corresponding virulent biotype was in a Hessian fly population. The second factor was the specific resistance gene used in the test. It appeared that the relationship was different between biotype frequency in a testing fly population and the percentage of susceptible plants in a virulence test for different resistance genes. Because we had only conducted a limited number of virulence assays and biotyped a limited number of Hessian fly females, we combined these data for establishing the logistic regression model. More virulence and biotype assays with different resistance genes will allow the establishment of linear regression model for each resistance genes. This will improve the accuracy and simplicity of the prediction model. Despite the need for improvement, the strong relationship between virulence frequency and the percent of susceptible plants in virulence tests suggests that it may be practical to predict biotype frequency based on virulence test results.

\section{Acknowledgments}

This research was partially supported by the grant USDANIFA-RAMP \#2010-51101-21642 (U.S. Department of Agriculture-National Institute of Food and Agriculture-Risk Avoidance and Mitigation). The Government of Ecuador and the Ecuador National Research Agriculture Institute (INIAP) supported Sandra Garcés-Carrera financially while she was at KSU to pursue her PhD.

\section{References Cited}

Alvey, D. P. 2009. Evaluation of the impact of Hessian fly (Mayetiola destructor) on Oklahoma winter wheat systems. M.S. thesis, Oklahoma State University, Stillwater, OK.

Bonferroni, C. E. 1935. Il calcolo delle assicurazioni su gruppi di test e, pp. 13-60. In Studi in Onore del Professore Salvatore Ortu Carboni. Bonferroni, Libreria Internazionale Seeber, Rome, Italy.

Buntin, G. D. 1992. Assessment of a microtube injection system for applying systemic insecticides at planting for Hessian fly control in winter wheat. Crop Protect. 11: 366-370.

Buntin, G. D. 1999. Hessian fly (Diptera: Cecidomyiidae) injury and loss of winter wheat grain yield and quality. J. Econ. Entomol. 92: 1190-1197.

Buntin, G. D., and P. L. Bruckner. 1990. Effect of planting date on Hessian fly infestation and production of triticale. Appl. Agric. Res. 5: 82-88.

Buntin, G. D., and R. D. Hudson. 1991. Spring control of the Hessian fly (Diptera: Cecidomyiidae) in winter wheat using insecticides. J. Econ. Entomol. 84: 1913-1919.

Buntin, G. D., S. L. Ott, and J. W. Johnson. 1992. Integration of plant resistance, insecticides, and planting date for management of the Hessian fly (Diptera: Cecidomyiidae) in winter wheat. J. Econ. Entomol. 85: 530-538.

Byers, R. A., and R. L. Gallun. 1971. Ability of the Hessian fly to stunt winter wheat. I. Effect of larval feeding on elongation of leaves. J. Econ. Entomol 65: 955-958.

Cambron, S. E., G. D. Buntin, R. Weisz, J. D. Holland, K. L. Flanders, B. J. Schemerhorn, and R. Shukle. 2010. Virulence in Hessian fly (Diptera: Cecidomyiidae) field collections from the Southeastern United States to 21 resistance genes in wheat. J. Econ. Entomol. 103: 2229-2235.

Chen, M. S., E. Echegaray, J. Whitworth, H. Wang, P. Sloderbeck, A. Knutson, K. Giles, and T. Royer. 2009. Virulence analysis of Hessian fly populations from Texas, Oklahoma, and Kansas. J. Econ. Entomol. 102: 774-780.

Chen, M. S., X. M. Liu, Z. Yang, H. Zhao, R. H. Shukle, J. J. Stuart, and S. Hulbert. 2010. Unconventional conservation among genes encoding small secreted salivary gland proteins from a gall midge. BMC Evol. Biol. 10: 296. 
Clement, S. L., L. R. Elberson, F. L. Young, R. H. Ratcliffe, J. R. Alldredge, and C. Hennings. 2003. Changing crop rotation and tillage practices increase Hessian fly populations in wheat. J. Kans. Entomol. Soc. 76: 567-577.

Comis, D. 2007. Virulent Hessian flies renew attack on U.S. wheat. U.S. Department of Agricultural Research-news and events. January 24, 2007. (http://www.ars.usda.gov/ is/pr/2007/070124.htm).

Colyer, P. D., P. R. Vernon, and T. Riley. 1989. First report of Hessian fly (Diptera: Cecidomyiidae) on winter wheat in Louisiana. J. Agric. Entomol. 7: 147-148.

Giles, K., and T. Royer. 2011. Characterization of insect populations and resistance in wheat. Partners in progress: wheat research at OSU 2010. Oklahoma State University. DASNR-OAES-OCES, Stillwater, OK.

Gould, F. 1998. Sustainability of transgenic insecticidal cultivars: Integrating pest genetics and ecology. Annu. Rev. Entomol. 43: 701-726.

Hoelscher. C. E., H. A. Turney, and M. C. Lidell. 1987. Hessian Oy in Texas wheat, p. 8. Texas Agricultural Extension Service, College Station, TX. Publication 8-1518.

Huang, F., S. Harrison, B. R. Leonard, M. Ghimire, and P. P. Price. 2011. Hessian fly, an emerging wheat pest in Louisiana. Louisiana Agriculture Magazine. (http://text. lsuagcenter.com/en/communications/publications/agmag/ Archive/2011/Winter/Hessian-Fly.htm).

Knutson, A., and J. Swart. 2007. Hessian fly outbreaks showing up in many north Texas wheat fields. Southwest Farm Report. (http:// southwestfarmpress.com/grains/041807hessian-fly/).

Li, C., M. S. Chen, S. Chao, J. Yu, and G. Bai. 2013. Identification of a novel gene, H34, in wheat using recombinant inbred lines and single nucleotide polymorphism markers. Theor. Appl. Genet. 126: 2065-2071.
Liu, X. M., G. L. Brown-Guedira, J. H. Hatchett, J. O. Owuoche, and M. S. Chen. 2005. Genetic characterization and molecular mapping of a Hessian fly resistance gene Hdic transferred from T. turgidum ssp. dicoccum to common wheat. Theor. Appl. Genet. 111: 1308-1315.

Morgan, G., C. Sansone, and A. Knutson. 2005. The Hessian Fly in Texas wheat. E-350. Texas AgriLife Extension Bulletin. (http:// agrilifebookstore.org).

Pauly, P. J. 2002. Fighting the Hessian fly. Environ Hist. 7: 385-507.

Ratcliffe, R. H., S. E. Cambron, K. L. Flanders, N. A. BosquePerez, S. L. Clement, and H. W. Ohm. 2000. Biotype composition of Hessian fly (Diptera: Cecidomyiidae) populations from the southeastern, Midwestern, and northwestern United States and virulence to resistance genes in wheat. J. Econ. Entomol. 93: 1319-1328.

Ratcliffe, R. H., and J. H. Hatchett. 1997. Biology and genetics of the Hessian fly and resistance in wheat, pp. 47-56. In K. Bondari (ed.), New Developments in Entomology. Research Signpost, Trivandrum, India.

Ratcliffe, R. H., G. G. Safranski, F. L. Patterson, H. W Ohm, and P. L. Taylor. 1994. Biotype status of Hessian fly (Diptera: Cecidomyiidae) populations from the eastern United States and their response to 14 Hessian fly resistance genes. J. Econ. Entomol. 87: 1113-1121.

Royer, T. A. 2005. Hessian fly reported in Oklahoma wheat. (http://www.ento.okstate.edu/Pddl/2005/PDIA4-1.pdf).

Smith, R. 2007. Widespread outbreaks of Hessian fly reported in wheat. Southwest Farm Report. (http:// southwestfarmpress.com/grains/ 051807-hessian-fly/).

Watson, S. 2005. Hessian fly problems have been increasing in recent years in the Central Plains. Wheat Farmer/ Row Crop Farmer 9: 4-5.

Received 26 August 2013; accepted 31 October 2013. 